\title{
Algumas reflexões sobre o corpo no cenário psicanalítico atual
}

\author{
Isabel Fortes ${ }^{\text {a* }}$ \\ Monah Winograd ${ }^{\mathrm{a}}$ \\ Simone Perelson ${ }^{\mathrm{b}}$ \\ aPontifícia Universidade Católica do Rio de Janeiro, Departamento de Psicologia. Rio de Janeiro, RJ, Brasil \\ bUniversidade Federal do Rio de Janeiro, Instituto de Psicologia. Rio de Janeiro, RJ, Brasil
}

\begin{abstract}
Resumo: Busca-se levantar indagações centrais acerca da presença do corpo na clínica psicanalítica e na cultura contemporânea. Para tal finalidade, examina-se o quanto essa problemática participa das transformações sociais testemunhadas nas últimas décadas. Em seguida, compara-se o corpo da biologia e o corpo da psicanálise, a fim de enfatizar a especificidade deste último. Esse problema remete à noção psicanalítica de corpo pulsional, aos limites da representação psíquica em psicanálise e à afirmação de que há nesse campo uma permeabilidade entre o registro da pulsão e o da representação. Além desses dois registros, o artigo propõe também incluir o corpo biológico como uma das dimensões do corpo metapsicológico em Freud.
\end{abstract}

Palavras-chave: corpo, psicanálise, clínica psicanalítica, contemporaneidade.

O objetivo deste artigo é mapear algumas questões cruciais sobre o corpo na psicanálise e na cultura contemporâneas que se apresentam como desafios para a clínica psicanalítica atual. Antes de mais nada, é importante sublinhar que o impacto causado nas subjetividades pelas transformações nas regulações sociais ocorridas nas últimas décadas tem ressonâncias diretas na clínica psicanalítica. Dentre estas transformações, a problemática do corpo tem se destacado devido, principalmente, ao fato de muitas das sintomatologias contemporâneas configurarem-se a partir dela.

Vejamos, primeiramente, o efeito dessas mudanças no campo do social, para, mais adiante, levantarmos alguns pontos que consideramos centrais no que se refere à clínica psicanalítica. Pelo lugar de predominância em que aparece na cultura e nos laços sociais, o corpo tem sido peça fundamental na constituição da subjetividade contemporânea, ao ponto de poder ser hoje denominado de "personalidade somática" (Costa, 2005). Ou seja, o indivíduo moderno tem baseado sua construção identitária na dupla referência ao corpo e ao cuidado consigo. De um lado, ser belo, magro e jovem tornou-se padrão de moralidade. De outro, ser longevo e saudável assumiu o lugar de imperativo, de modo que a valorização da qualidade de vida se inseriu no modelo prototípico da identidade atual - a bioidentidade -, transformando a forma de cuidar de si em culto ao corpo, visto como bem supremo. Se, antes da ocorrência de tais mudanças, o cuidado de si era dirigido ao cultivo da alma e da interioridade, ao desenvolvimento das virtudes morais e dos sentimentos, hoje ele está voltado para o campo da saúde, da beleza, da boa forma, ou seja, para os signos da subjetividade inscritos mais no âmbito da exterioridade

* Endereço para correspondência: mariaisabelfortes@gmail.com do que no da interioridade (Birman, 1999; Costa, 2005; Fernandes, 2003; Fortes, 2010).

Trata-se de questão problemática para uma psicanálise constituída, desde seu nascimento, como terapêutica inserida no domínio da linguagem e sustentada primordialmente pelo registro da fala. Muitos autores (Assoun, 2009; Birman, 1999; Costa, 2005; Fernandes, 2003; Queiroz, 2008; Winograd, 2003) têm não apenas demonstrado o quanto a dimensão corporal foi historicamente negligenciada pela psicanálise - cujo modus operandi contribuiu para sua exclusão - como também, nos últimos tempos, têm buscado trabalhar essa noção de forma mais sistemática e consistente. Um dos motivos para essa negligência se deve à antiga tradição - ainda seguida por algumas regiões do campo psicanalítico - de definir o corpo por oposição a um psiquismo descrito comumente como, por excelência, representacional. Dito de outro modo, apesar de a teoria freudiana ter consolidado os conceitos de inconsciente $\mathrm{e}$ de pulsão e, com isso, construído instrumentos teóricos suficientes para problematizar e mesmo superar essa oposição, a psicanálise se viu, ao longo do tempo, limitada a uma leitura dos processos psíquicos a partir da representação e do significante. Além disso, a redução do corpo à referência fisicalista, característica do discurso científico hegemônico, fez com que fosse reforçado, também na psicanálise, o dualismo psicofísico da psicologia introspectiva do século XIX. Essa relação de distanciamento que a psicanálise manteve com o corpo acarretou, segundo Fernandes (2003), um duplo movimento: esquecido, foi absorvido pela psicossomática que, entretanto, sempre deu ênfase ao corpo doente.

Desse modo, discutir a presença da dimensão corpórea na psicanálise é algo necessário, uma vez que o referencial psicanalítico tradicional tem operado 
usualmente desde o campo da linguagem e na aposta de um tratamento que se produz por meio da palavra, ao custo de uma expulsão do corpo e, a reboque, do afeto. No esteio dessa problemática, várias reflexões surgem como propulsoras de indagações importantes para a clínica psicanalítica contemporânea. A questão que aqui se coloca é sobre como empreender uma clínica com pacientes que fazem do corpo - e estritamente dele não somente o seu sintoma, mas sua própria forma de ser. Dito de outro modo, a partir da observação de, cada vez mais, formações sintomáticas graves, configuradas a partir do e, sobretudo, no corpo, é preciso perguntar sobre o impacto clínico do imperativo cultural atual do culto ao corpo, o qual, muito possivelmente, intensifica as dificuldades de expressão simbólica de sujeitos marcados por organizações narcísicas frágeis.

Nesse sentido, problematizaremos, agora, alguns pontos que consideramos centrais para a discussão sobre o lugar do corpo no cenário psicanalítico atual. Nossa proposta não é aprofundar as questões levantadas, mas esboçar um mapeamento que delineie reflexões hoje contundentes e fundamentais para pensar o registro do corpo na psicanálise.

\section{O lugar do corpo hoje}

Ao propormos uma interrogação clínica sobre algumas lógicas e alguns efeitos da subjetivação na cultura, partimos da premissa de que existe uma atualidade social da metapsicologia (Douville, 2004). O inconsciente psicanalítico não se constitui de maneira solipsista, como apontaram Freud, ao defender que não há separação entre a psicologia individual e a psicologia social, e também Lacan, quando salientou o caráter transindividual do inconsciente. Daí ser necessário, para formular questões fundamentais para o mapeamento sobre o tema do corpo tanto na cultura como na clínica atuais, descrever o cenário que erigiu o corpo como bem supremo.

Nas últimas décadas, constituiu-se, no Ocidente, uma cartografia nova do social articulada à elaboração de uma forma inédita de subjetivação, na qual o eu se localizaria em posição privilegiada (Birman, 1999; Lasch, 1979; Sibilia, 2008). Com efeito, o privilégio dado ao eu tem sido uma das características principais da assim chamada sociedade do espetáculo (Debord, 1968/1997), atravessada pelo narcisismo (Lasch, 1979). Estamos diante de um modo de produção subjetiva simultânea e paradoxalmente movido pelo valor dado à exterioridade e pelo autocentramento no eu (Birman, 1999). Nesse mundo, marcado pelo calibre do que aparece no e do que importa para o exterior - e não mais pelo refinamento e enriquecimento da interioridade -, a dimensão do corpo ganhou relevo como a materialização, por excelência, da ordem da exterioridade nos parâmetros da subjetividade.

A referência a esse contexto do espetáculo e da exterioridade marcou diversas leituras a respeito do aumento das práticas e técnicas de modificação corporal, incluídas aí desde as intervenções eletivas e as manipulações irreversíveis para mudar o tamanho e o formato de várias partes do corpo até as inscrições, com tinta ou cicatrizes, de signos em sua superfície. Por exemplo, a cultura da tatuagem foi compreendida por Birman (2011) como uma das formas de singularização buscada pelos jovens de hoje diante da invisibilidade identitária em que se encontram. De modo similar, Mielli (2002) interpretou as modificações corporais em geral como uma busca por landmarks - pontos de referência, balizas, marcos -, pelos quais o sujeito visaria constituir um território simbólico, um traço de identificação que oferecesse contorno a uma forma fluida. Mas, se a instabilidade atual do corpo é condição para o incremento de práticas que pretendem lhe dar uma espécie de âncora identificatória, observamos que, ao mesmo tempo, as possibilidades infinitas contidas nessas mesmas práticas reforçam a experiência contemporânea de um corpo mutante e instável (Mielli, 2002; Orbach, 2009).

Ao mesmo tempo, embora mutante e instável, o corpo também se tornou o locus das preocupações de um sujeito constituído a partir do imperativo de uma imagem corporal ideal, quer em sua forma, segundo os parâmetros de beleza, quer em sua fisiologia, segundo os paradigmas da saúde. Em um mundo saturado de imagens (Debord, 1968/1997), também o corpo se tornou estampa, de tal modo que a busca desesperada pela imagem ideal levou ao empobrecimento das formas de expressão corporal e dos próprios conceitos do que seria belo, saudável e normal. Dito de outro modo, apesar de termos testemunhado um exacerbamento das imagens, apenas algumas dentre elas tornaram-se imperatórias, levando, paradoxalmente, à depreciação das formas do corpo que fujam dos modelos estabelecidos (Orbach, 2009). Ainda que, desde muito recentemente, estejamos assistindo a tentativas de valorizar corpos gordos, flácidos, defeituosos, velhos etc., mediante, por exemplo, a proliferação de discursos em favor da diversidade dos padrões em geral (estéticos, de gênero etc.) e de campanhas publicitárias que os capturam com objetivos próprios, o respeito e a valorização dessa multiplicidade são, a nosso ver, ainda tímidos. $\mathrm{O}$ tratamento digital das imagens veiculadas na mídia, para que os corpos pareçam perfeitos e as rugas inexistentes, segue sendo regra, apesar da multiplicação das denúncias da artificialidade dos modelos assim construídos.

Contudo, essas problemáticas das modificações corporais e dos corpos ideais não são as únicas vias para se pensar o lugar do corpo na atualidade. Há, ainda, a questão não menos importante do chamado sujeito cerebral (Ehrenberg, 2004/2009), forjado pelas neurociências. Ao longo da segunda metade do século XX, essa figura ganhou terreno no domínio da cultura: cada vez mais os indivíduos acreditam ser, principalmente, efeito de processos neuroquímicos. A ideia de um sujeito definido e determinado por sua 
neurofisiologia é tributária do lugar dominante que a biologia vem ocupando na ciência e no pensamento do século XXI, devido, entre outros, aos avanços em diversos campos, tais como a biologia molecular, o mapeamento do genoma humano, as tecnologias de clonagem e de reprodução assistida, a produção de novos medicamentos etc. Especificamente, a evolução das técnicas de imageria cerebral, aliada à interpretação fisicalista das imagens assim produzidas, ajudaram a construir a crença de que entender o funcionamento do cérebro equivaleria a entender o sujeito em sua totalidade (Ortega, 2008). Ao mesmo tempo, os dados produzidos pela tecnologia de visualização do cérebro em funcionamento e sua correlação com processos psíquicos reacendeu questões clássicas e engendrou um debate importante - hoje bem menos intenso - entre neurociências e psicanálise.

Nesse debate, foi possível observar a constituição de três eixos gerais. $\mathrm{O}$ primeiro entendia ser preciso compor um campo híbrido, pois as neurociências poderiam oferecer à psicanálise fundamentos e instrumentos metodológicos (científicos) mais sólidos para a pesquisa do funcionamento psíquico. Esse discurso consolidou-se com a fundação da neuropsicanálise. O segundo eixo era completamente refratário a qualquer tipo de interlocução, por entendê-la como epistemologicamente inviável e resultando necessariamente numa submissão da psicanálise ao cientificismo atual. Finalmente, entre um e outro, o terceiro eixo, assumindo uma posição não reducionista forte, defendia o pluralismo teórico e metodológico na produção de conhecimento sobre o psiquismo humano e reconhecia a importância da exploração da problemática da corporeidade na vida psíquica, referida não apenas à questão das representações conscientes e inconscientes do corpo, mas, sobretudo, à sua função determinante na constituição, na economia e no funcionamento psíquicos.

\section{O corpo da biologia e o corpo da psicanálise}

Diante da dominância, anteriormente destacada, da ordem do biológico nas construções discursivas científicas da atualidade, consideramos relevante analisar de qual corpo se trata na psicanálise. Para essa finalidade, cabe enfatizar a dimensão pulsional do corpo por meio de breve problematização sobre o lugar do biológico na psicanálise. Podemos pensar que, se o corpo, tal como Freud o conceitua, não se confunde com o organismo (biológico), ele também não se define apenas por suas inscrições simbólica e imaginária. Para a psicanálise (e não apenas a freudiana), pela sua pulsionalidade, o corpo se constitui na interseção entre o psíquico e o somático, ou seja, no jogo complexo e multidimensional entre o material (o orgânico), o imaterial (o representacional) e uma espécie de mistura indiscernível entre os dois (o pulsional). De tal modo que, para circunscrever essa problemática e elaborar reflexões sobre ela, esses três registros precisam, necessariamente, ser levados em consideração.

Com efeito, quando Freud demonstrou que o corpo revelado pela histeria se distanciava do da anatomia, foi porque ele entendeu tratar-se de um corpo atravessado pela linguagem popular e não pela científica. Essa diferença entre o corpo científico e o corpo popular, evidenciada de forma exemplar pelo sintoma de conversão histérica, inaugurou a distinção entre o corpo da biologia e o corpo da psicanálise - o que foi claramente formulado quando o inventor da psicanálise concluiu que a histeria se comportava como se a anatomia não existisse ou como se não tivesse conhecimento dela. Ora, o que estava em jogo nos sintomas histéricos, tão comuns naquela época, era a representação simbólica, mais precisamente aquela da linguagem popular dos órgãos e do corpo em geral. Por isso, as paralisias ou as cegueiras histéricas não tinham como causa lesões ou disfunções dos órgãos envolvidos, sendo, em verdade, efeitos dos processos representacionais. A se considerar alguma lesão, como atestou Freud em 1893, esta se localizaria na ideia do braço e não no próprio braço (Freud, 1893/1976). O corpo da histeria seria doente, então, de sua representação simbólica, e não de uma lesão anatomoclínica. Esse aspecto apenas seria suficiente para que afirmássemos que a noção de corpo em psicanálise é mais ampla e complexa do que a de um corpo-organismo, já que se trata aqui também de um corpo-sujeito que condensa as dimensões simbólica e imaginária.

Porém, se não há dúvidas de que a invenção do inconsciente só foi possível a partir da ruptura com o corpo anatomofisiológico da medicina, isso não quer dizer que o corpo em Freud seja um mero decalque representacional. Ou seja, o corpo, em sua materialidade biológica, não pode ser descartado como uma das determinações dos processos psíquicos. Mas, se é assim, devemos perguntar: qual o lugar do biológico no pensamento freudiano? Para além da lógica da representação, encontraríamos exclusivamente a dimensão pulsional ou também o orgânico ao qual esse pulsional se articularia? Para responder a essas questões, é preciso retomar as noções freudianas de apoio e de estado de urgência da vida.

Para analisar essas duas noções, precisamos, primeiro, diferenciar a leitura clássica da teoria freudiana do apoio e a circunscrição que a referência ao orgânico teve na teoria lacaniana (Lacan, 1955/1985, 1964/1985). De acordo com a leitura clássica da teoria do apoio formulada por Freud (1905/1976) em "Três ensaios sobre a teoria da sexualidade", num primeiro momento, simultaneamente à satisfação das necessidades vitais próprias à manutenção da vida e à autoconservação, também ocorreria a satisfação sexual decorrente da erogenização das zonas ou dos órgãos envolvidos nas necessidades vitais e em contato com o objeto que proporcionou a satisfação. A partir daí as pulsões sexuais tornar-se-iam gradativamente independentes das necessidades vitais, impondo, constantemente, uma 
busca pela repetição da satisfação sexual primeira. Assim, por um lado, o apoio designaria a relação coincidente originária entre as pulsões e as funções vitais, as quais seriam sua fonte somática e lhes forneceriam, num momento inicial, uma direção específica. Por outro lado, ele também sublinharia o abismo entre a pulsionalidade e as funções vitais. Dito de outro modo, o apoio indicaria, ao mesmo tempo, a relação primitiva íntima e ao mesmo tempo a distância profunda entre as ordens da sexualidade e da conservação da vida, apontando para a relação tanto de coincidência quanto de desvio entre autoconservação e sexualidade. Daí essa noção ser chave para a compreensão da pulsão (sexual), concebida como o efeito marginal desse apoio-desvio e como ruptura com a ordem do natural. Aqui, cabe também lembrar o aprofundamento, a revisão e a leitura singular da noção de apoio realizados por Laplanche e Pontalis. Segundo Garcia-Roza (1995), o mérito de dar destaque a essa noção deve ser creditado a Laplanche, que se deteve sobre ela com uma extensão ainda maior, inclusive, do que a que Freud lhe atribuiu (Garcia-Roza, 1995, p. 108).

Mais de 50 anos depois da formulação da teoria do apoio, Jacques Lacan aventou uma perspectiva diferente da proposta por Freud. Enquanto este associava o surgimento da pulsão sexual a uma fonte orgânica correspondente à necessidade vital, Lacan (1964/1985) relacionou a referência orgânica a um estado de urgência da vida que, diferentemente de Freud, imporia já de antemão a parcialidade e a independência das pulsões. Para o psicanalista francês, o campo pulsional não apenas não se confundiria, sequer num início mítico, com as fontes somáticas, como apontaria para uma não adaptação radical do ser humano. Se, na leitura da teoria freudiana, a satisfação inicial da pulsão sexual derivaria da estimulação da zona oral durante a alimentação, podemos observar que, em Lacan, a dimensão do biológico não envolveria o fornecimento de uma direção inicial específica.

A circunscrição do campo do biológico em Lacan, muito mais do que se associar à noção de apoio, busca reforçar a compreensão da precariedade do corpo humano. A ideia de que há uma prematuridade biológica no humano se liga ao fato da necessidade de uma antecipação do imaginário para a formação do eu enquanto uma unidade (Lacan, 1949/1966). Para o psicanalista francês, há uma distância radical entre os órgãos e as funções e é essa não associação entre os dois a condição para o surgimento do corpo erógeno entendido como corpo parcializado. Sem função já determinada, o órgão pode adquirir uma função erogenizada (Leclaire, 1979/1992; Miller, 1999). Daí advém a crítica lacaniana à ideia de apoio. A sexualidade estaria, desde sempre, descolada do biológico, ou seja, marcada pela incapacidade de plena satisfação. O Not des Lebens seria o fato da premência de satisfação em geral e não a coincidência entre a pulsão, sua fonte somática e, portanto, a direção para a obtenção da satisfação. Como sublinhou Lacan (1964/1985), a satisfação oral não vem da ingestão do alimento, mas do prazer de que a própria boca é capaz. O estado de urgência da vida não designaria, portanto, uma referência a necessidades vitais específicas tais como a nutrição, entre outras, mas expressaria a necessidade geral de satisfação por meio de diversos modos e objetos infinitamente variáveis. Em outras palavras, como salienta Assoun (2009), o olhar lacaniano para o registro do biológico teria a finalidade de dar ênfase à importância da parcialidade para o estatuto de corpo em psicanálise. O recorte, nessa visão, não se daria pela noção de apoio, mas pela noção de prazer de órgão, que tem o mérito de fazer a liga entre o organismo vivente e a vida inconsciente dos órgãos. O prazer de órgão foi um dos termos usados por Freud para se contrapor à ideia de um prazer que seria ligado a uma função vital. Resultante da satisfação das necessidades vitais, ele expressaria justamente a dimensão da parcialidade que compõe o que Assoun (2009) denominou de "organologia freudiana". Vê-se, aqui, como a referência à biologia é importante, porque enfatiza que a excitação perpassa os órgãos, caracterizando a satisfação autoerótica das pulsões parciais.

Todavia, segundo Miller (2000), o sentido dessa importância foi atualizado a partir do advento da biologia molecular, a qual, em suas palavras, ofereceu uma sustentação "à tese de Lacan que o Um será capturado a partir do significante e não a partir da natureza" (p. 10). Na leitura de Miller, a biologia molecular serve, sobretudo, como referência para a concepção de corpo despedaçado, uma vez que reforça a ideia que o vivo se apresenta originariamente em sua molecularidade, isto é, em sua fragmentação. Isso renovaria o entendimento que o corpo, enquanto instância unificada, é efeito da incidência da ordem imaginária. Além disso, ainda segundo a leitura milleriana, a noção lacaniana de corpo vivo, articulada ao conceito de gozo, pode sustentar a presença da biologia na teoria, na medida em que aponta para uma dimensão "nem imaginária, nem simbólica, mas vivente, eis o corpo que é afetado pelo gozo" (p. 17).

Seja como for, o que há em comum a essas possíveis leituras sobre o lugar da biologia na concepção psicanalítica do corpo é a ideia que o corpo, em sua processualidade, impele o sujeito para a busca de uma satisfação sempre parcial, a qual transcende a manutenção da vida e cuja possível unidade é somente imaginária. Desde o início da psicanálise e apesar de asseverar a importância do recobrimento simbólico do corpo, Freud entendeu que este não pode ser reduzido à dimensão representacional, porque é fonte de uma pulsionalidade que pressiona insistente e constantemente, desfazendo e refazendo as articulações simbólicas. Por isso, Leclaire (1979/1992) pôde salientar que, concomitante e articuladamente à teoria do simbólico, também há, na teoria freudiana da sexualidade, o que pode ser circunscrito como "a capacidade do corpo vivo". Abandonar as concepções anatomofisiológicas do corpo não conduziu necessariamente ao seu apagamento: o corpo pulsional ainda é o corpo vivo, distinto do corpo anatomofisiológico porque mais amplo em sua capacidade 
de resposta à tensão pulsional. Ou seja, trata-se de um corpo movido por uma pressão pulsional que, não só precisa ser descarregada, como também não pode ser recoberta em sua totalidade pela linguagem. Há sempre um resto.

\section{O corpo pulsional: os limites da representação psíquica}

A abordagem freudiana do corpo, portanto, envolve tanto o representacional como o pulsional, sem que esses registros possam ser separados, pois a pulsão se expressa por meio de seus representantes, dos quais pelo menos um está necessariamente inserido na dimensão da linguagem. Podemos, portanto, afirmar haver uma indiscernibilidade básica entre os dois registros e uma permeabilidade que vão de encontro a qualquer dicotomia entre representação e pulsão: a representação é, por definição, um dos modos de expressão da pulsão. Em outras palavras, é preciso sempre sublinhar a dimensão intensiva e pulsional da linguagem, sem a qual ela é palavra morta.

Entretanto, dizer que pulsão e representação são indiscerníveis não significa absolutamente dizer que suas lógicas sejam as mesmas. Como bem apontado por David-Ménard (2000), se há, em Freud, uma relação direta entre gozo sexual e pensamento, a diferença entre eles estaria nos níveis de energia que cada um envolve. Com efeito, em "Formulações sobre os dois princípios do funcionamento psíquico", Freud (1911/1976) mostrou não haver oposição entre a busca de prazer e o ato de pensar. Enquanto o primeiro visaria à descarga imediata - princípio do prazer -, o segundo resultaria do e operaria um adiamento dessa descarga em prol de uma satisfação mais efetiva - princípio de realidade. Ambos os princípios visariam, em última instância, à descarga e à satisfação: gozar e pensar seriam, assim, expressão dos modos de distribuição de energia no aparelho psíquico. O que permitiria a atividade do pensamento seria o adiamento do prazer e da descarga, o que não se contraporia nem ao gozo sexual nem à ordem do corpo pulsional.

Por isso, porque o corpo vivo é gozo e pensamento, paixão e espírito, podemos perceber como o pensamento freudiano dissolveu o dualismo de substância cartesiano, para o qual corpo e pensamento seriam radicalmente distintos e não precisariam de nada além de si mesmos para existirem. A teoria freudiana, ao contrário e apesar das dualidades pulsionais de 1905 e de 1920, assenta-se sobre um monismo pulsional: sexual ou de autoconservação, de vida ou de morte, é sempre do mesmo corpo pulsional que se trata. De resto, apenas a alternância entre modos diferentes de inscrição psíquica e de descarga materializada, seja imediatamente no e pelo corpo, seja na sua inibição e no seu adiamento, condição de possibilidade do pensamento. Assim, o que está em jogo é o modo como as intensidades são (ou não) reguladas. Por isso, David-Ménard (2000) propõe que o psiquismo seja definido como um aparelho de prazerdesprazer e de angústia e, ao mesmo tempo, como um aparelho de pensar que coloca em ação movimentos que visam a atender à finalidade de satisfação e de gozo. Ou seja, para David-Ménard, se "o corpo histérico pensa" (p. 17), isso se dá pelo fato de que há uma permeabilidade necessária, entre corpo, gozo e representação, opondo-se, dessa maneira, a que haja um pensamento dualista na obra freudiana.

Essa questão é importante por lançar luz sobre a definição psicanalítica de psiquismo, a qual, por motivos variados ao longo de sua história, remeteu muitas vezes preponderantemente ao lugar das representações e, com isso, acabou reforçando a dominância representacional e do significante. Ocorre que, como vimos, para além dessa dimensão representacional e tão fundamental quanto ela, o conceito de pulsão se apresenta como o terreno teórico que revela, na metapsicologia, a indistinção substancial entre corpo e psiquismo. Com efeito, Freud (1915/1976) iniciou o ensaio "Os instintos e suas vicissitudes" associando e, ao mesmo tempo, diferenciando a pulsão do estímulo fisiológico, a partir do modelo do arco reflexo. Se não há como fugir da pressão incessante exercida pela pulsão - esse é o argumento principal do ensaio freudiano de 1915 - faz-se necessário buscar destinos possíveis para a excitação pulsional. A fonte da pulsão é a processualidade somática, mas seus destinos envolvem os processos psíquicos que, por sua vez, retornam necessariamente sobre esse corpo. Derivada do corpo, a pulsão retorna sobre ele, fazendo dele, ao mesmo tempo, origem e destino. O corpo é, a um só tempo, a fonte da pulsão e o veículo que permite a descarga conducente à experiência de satisfação (Andrade, 2003; Birman, 2009; Winograd \& Mendes, 2009).

A partir de 1920, com a formulação freudiana do conceito de pulsão de morte, a dinâmica pulsional foi inscrita além do princípio de prazer, no qual o princípio de nirvana faria com que o aparelho psíquico tendesse a zerar toda a quantidade de estímulo recebida. A pulsão de morte foi definida como sendo o que causaria disjunções no psiquismo e, no limite, a decomposição do aparelho psíquico, cabendo à pulsão de vida, por oposição, a característica de promover a ligação das excitações internamente circulantes. Mais profundamente, quando desintrincada da pulsão de vida, a pulsão de morte acionaria movimentos que aspirariam à descarga total. Isso porque a desfusão das pulsões levaria a seu aumento abrupto num movimento súbito, brusco e traumático como efeito do transbordamento do que não foi capturado pelas ligações psíquicas (Fortes, 2008).

Trocando em miúdos, se entendemos que a pulsionalidade é expressão de uma corporeidade jamais inteiramente recoberta pela representação, podemos afirmar, invertendo o raciocínio, que o corpo pulsional está na origem e nos limites da representação. $\mathrm{Na}$ região aquém e além do princípio de prazer, trata-se do pulsional excessivo porque não ligado e recoberto representacionalmente, cujas descargas abruptas e cujos movimentos violentos de intensificação e escoamento 
operam a partir do corpo e em direção a ele. Agora, não se trata mais do corpo histérico e simbólico paradigmático do início da psicanálise, mas de um corpo intensivo e excessivo.

Portanto, para Fernandes $(2003,2011)$ são duas as dimensões da abordagem freudiana do corpo: a simbólica e a excessiva. Entre elas, há sempre uma tensão entre o que Fernandes $(2003,2011)$ chamou de corpo da representação e corpo do transbordamento pulsional. A autora propõe que há uma dupla incidência do lugar do corpo na teoria freudiana, uma dupla racionalidade, indicando que as duas vias - corpo representacional e corpo do transbordamento - refletem os traços centrais da função metapsicológica do corpo e oferecem uma via fecunda de compreensibilidade de sua presença tanto na teoria quanto na clínica.

Nesse mesmo viés, Winograd e Mendes salientam que para entendermos que corpo se trata em psicanálise é fundamental levarmos em conta que Freud não abordou o corpo somente em seu aspecto simbólico e imaginário, mas também nos registros biológico e pulsional. Para elas, inclusive, não se restringe a duas as dimensões possíveis do corpo na visão freudiana, mas alargam para pensarmos também a possibilidade do corpo biológico na obra desse autor. Como dito, pode-se aventar a existência dos três registros de corpo biológico, representacional e pulsional para o quadro de uma metapsicologia do corpo em Freud, entendendo que os registros não são isolados, mas têm impactos e reverberações entre eles.
Nessa perspectiva, o exame dos vários aspectos do corpo metapsicológico nos importa particularmente, ao propormos traçar um mapeamento geral de questões centrais sobre o tema do corpo na teoria freudiana. A ideia de que há uma dupla racionalidade do lugar do corpo na teoria freudiana e o destaque para a importância da biologia como sendo igualmente determinante do que se passa no sujeito são temas, a nosso ver, fundamentais para a proposta deste artigo, qual seja, levantar alguns pontos de reflexão para o debate atual sobre o tema do corpo em psicanálise.

\section{Conclusão}

Concluindo, buscamos neste artigo traçar um panorama sobre o lugar do corpo no cenário psicanalítico atual, destacando alguns eixos de análise e investigação que consideramos centrais para a compreensão do atual enquadre conceitual e clínico dessa problemática. Nessa perspectiva, consideramos que as discussões acerca da ênfase que a cultura hodierna dá ao corpo e as incidências dessa ênfase na clínica psicanalítica precisam ser pensadas na sua articulação com o corpo metapsicológico, aqui abordado em seus diferentes aspectos, quais sejam, os registros do corpo pulsional, do corpo biológico e do corpo representacional na psicanálise, peças-chave conceituais que merecem ser mais aprofundadas para uma ampliação da compreensão psicanalítica acerca dessa temática, que ajude ao psicanalista nos confrontos e desafios colocados pela clínica da atualidade.

\section{Some considerations about the body in the current psychoanalytic scenario}

Abstract: This article seeks to raise some central questions about the presence of the body in psychoanalytic clinical practice and contemporary culture. For such, it examines how this problem appears in the social transformations witnessed in the last decades. The biology body and the psychoanalysis body are then compared to emphasize the specificity of the latter. This problem refers to the psychoanalytic notion of the drive body, to the limits of psychic representation in psychoanalysis, and to the assertion that there is, in this field, a basic indiscernibility between the context of the drive and that of representation. In addition to these two aspects, the article highlights the importance of including the biological body as one of the dimensions of the metapsychological body in Freud.

Keywords: body, psychoanalysis, psychoanalytic clinic, contemporaneity.

\section{Quelques réflexions sur le corps dans le scénario psychanalytique actuel}

Résumé: On cherche à soulever des questions centrales au sujet de la présence du corps dans la clinique psychanalytique et la culture contemporaine. À cet effet, on examine comment cette problématique participe des transformations sociales témoignées au cours des dernières décennies. Ensuite on compare le corps de la biologie au corps de la psychanalyse pour souligner la spécificité de celui-ci. Ce problème renvoie à la notion psychanalytique du corps pulsionnel, aux limites de la représentation psychique en psychanalyse et à l'affirmation selon laquelle il y a dans ce domaine une indiscernabilité basique entre le registre de la pulsion et celui de la répresentation. En plus de ces deux dimensions, l'article souligne l'importance d'inclure le corps biologique comme l'une des dimensions du corps métapsychologique en Freud.

Mots-clés: corps, la psychanalyse, la clinique psychanalytique, contemporanéité. 


\section{Algunas reflexiones sobre el cuerpo en la escena psicoanalítica actual}

Resumen: Se busca levantar indagaciones centrales sobre la presencia del cuerpo en la clínica psicoanalítica y en la cultura contemporánea. Con este propósito, se examina cuánto esta problemática participa en las transformaciones sociales atestiguadas en las últimas décadas. Enseguida se compara el cuerpo de la biología con el cuerpo del psicoanálisis, a fin de enfatizar la especificidad de este último. Este problema se remite a la noción psicoanalítica de cuerpo pulsional, a los límites de la representación psíquica en el psicoanálisis y a la afirmación de que hay en este campo una indiscernibilidad básica entre el registro de la pulsión y el de la representación Además de estos dos registros, el artículo destaca la importancia de incluir también el cuerpo biológico como una de las dimensiones del cuerpo metapsicológico en Freud. Palabras clave: cuerpo, psicoanálisis, línica psicoanalítica, contemporaneidade.

Palabras clave: cuerpo, psicoanálisis, línica psicoanalítica, contemporaneidade.

\section{Referências}

Andrade, C. B. (2003). A natureza do corpo: origem ou destino? Cadernos de Psicanálise, 19(22), 97-112.

Assoun, P.L. (2009). Corps et symptôme (3a ed.). Paris, France: Anthopos.

Birman, J. (1999). Mal-estar na atualidade. A psicanálise e as novas formas de subjetivação. Rio de Janeiro, RJ: Civilização Brasileira.

Birman, J. (2009). As pulsões e seus destinos: do corporal ao psíquico. Rio de Janeiro, RJ: Civilização Brasileira.

Birman, J. (2011). Tatuando o desamparo: a juventude na atualidade. Epos, 1(2), 15-26.

Costa, J. F. (2005). O vestígio e a aura: corpo e consumismo na moral do espetáculo. Rio de Janeiro, RJ: Garamond.

David-Ménard, M. (2000). A histérica entre Freud e Lacan. São Paulo, SP: Escuta.

Debord, G. (1997). A sociedade do espetáculo. Rio de Janeiro, RJ: Contraponto. (Trabalho original publicado em 1968).

Douville, O. (2004). Uma melancolização do laço social? Ágora - Estudos em Teoria Psicanalítica, 7(2), 179-201.

Ehrenberg, A. (2009). O sujeito cerebral. Psicologia Clínica, 21(1), 187-213. (Trabalho original publicado em 2004).

Fernandes, M. H. (2003). Corpo. São Paulo, SP: Casa do Psicólogo.

Fernandes, M. H. (2011). As relações entre o psíquico e o somático: o corpo na clínica psicanalítica. In C. A. Garcia \& M. R. Cardoso, Limites da clínica (pp. 47-62). Clínica dos limites. Rio de Janeiro, RJ: Cia de Freud.

Fortes, I. (2008). A dimensão do excesso no sofrimento contemporâneo. Pulsional Revista de Psicanálise, 21(3), 63-74. São Paulo, SP: Escuta.

Fortes, I. (2010). O corpo na clínica contemporânea e a anorexia mental. In J. Birman, I. Fortes \& S. Perelson, Um novo lance de dados: psicanálise e medicina na contemporaneidade (pp. 73-88). Rio de Janeiro, RJ: Cia de Freud.

Freud, S. (1976). Um estudo comparativo das paralisias motoras orgânicas e histéricas. In Edição standard brasileira das obras psicológicas completas de Sigmund Freud (Vol. I, pp. 219-242X). Rio de Janeiro, RJ: Imago. (Trabalho original publicado em 1893).
Freud, S. (1976). Três ensaios sobre a teoria da sexualidade. In Edição standard brasileira das obras psicológicas completas de Sigmund Freud (Vol. VII, pp. 123-253). Rio de Janeiro, RJ: Imago. (Trabalho original publicado em 1905).

Freud, S. (1976). Formulações sobre os dois princípios do funcionamento psíquico. In Edição standard brasileira das obras psicológicas completas de Sigmund Freud (Vol. XII, pp. 277-288). Rio de Janeiro, RJ: Imago. (Trabalho original publicado em 1911).

Freud, S. (1976). Os instintos e suas vicissitudes. In Edição standard brasileira das obras psicológicas completas de Sigmund Freud (Vol. XIV, pp. 123-146). Rio de Janeiro, RJ: Imago. (Trabalho original publicado em 1915).

Garcia-Roza, L.A. (1995). Pulsão e instinto: o conceito de apoio. In L.-A. Garcia-Roza, Introdução à metapsicologia freudiana (Vol. 3, pp. 103-118). Rio de Janeiro, RJ: Jorge Zahar.

Lacan, J. (1966). Le stade du miroir comme formateur de la fonction du Je. In Écrits (pp. 93-100). Paris, France: Seuil. (Trabalho original publicado em 1949).

Lacan, J. (1985). O Seminário livro 3: as psicoses. Rio de Janeiro, RJ: Jorge Zahar. (Trabalho original publicado em 1955).

Lacan, J. (1985). O Seminário livro 11: os quatro conceitos fundamentais da psicanálise. Rio de Janeiro, RJ: Jorge Zahar. (Trabalho original publicado em 1964).

Lasch, C. (1979). The culture of narcissism. New York, EUA: Norton.

Leclaire, S. (1992). O corpo erógeno. São Paulo, SP: Escuta. (Trabalho original publicado em 1979).

Mielli, P. (2002). Sobre as manipulações irreversíveis do corpo. Rio de Janeiro, RJ: Contracapa.

Miller, J.A. (1999). Elementos de biologia lacaniana. Belo Horizonte, MG: Escola Brasileira de Psicanálise.

Miller, J.A. (2000). Biologie lacanienne et événement de corps. La cause freudienne - Revue de Psychanalyse, 44, 5-55.

Orbach, S. (2009). Bodies. New York, USA: First Picador.

Ortega, F. (2008). O corpo incerto: corporeidade, tecnologias médicas e cultura contemporânea. Rio de Janeiro, RJ: Garamond. 
Queiroz, E. F. (2008). O inconsciente é psicossomático. Revista Mal-estar e Subjetividade, 8(4), 911-924.

Sibilia, P. (2008). O show do eu: a intimidade como espetáculo. Rio de Janeiro, RJ: Nova Fronteira.

Winograd, M. (2003). A problemática corpo-alma na obra freudiana. Cadernos de psicanálise, 19(22), 227-248. Rio de Janeiro.
Winograd, M.; \& Mendes, L. C. (2009). Qual corpo para a psicanálise? Breve ensaio sobre o problema do corpo na obra de Freud. Psicologia: Teoria e Prática, 11(2), 211-223.

Recebido: $27 / 11 / 2017$

Aprovado: 23/02/2018 